\title{
Da Vulnerabilidade como Condição de Saber nas Pesquisas em Psicologia Social
}

\author{
Wanderson Vilton Nunes da Silva ${ }^{1}$ \\ ${ }^{1}$ Universidade Federal de Pernambuco, PE, Brasil.
}

\author{
Simone Maria Hüning ${ }^{2}$ \\ ${ }^{2}$ Universidade Federal de Alagoas, AL, Brasil.
}

\author{
Neuza Guareschi ${ }^{3}$ \\ ${ }^{3}$ Universidade Federal do Rio Grande do Sul, RS, Brasil.
}

\begin{abstract}
Resumo: Neste artigo buscamos problematizar a função das narrativas e da ideia de vulnerabilidade nos modos de construir conhecimento em psicologia social. A construção de conhecimento tem sido deslocada da noção de experiência, associando-se à contagem numérica e a uma pretensa habilidade do pesquisador em objetificar seu campo de estudo. Propomos fazer da experiência em acompanhar equipes de saúde nos campos de pesquisa um elemento para a análise da construção de outra objetividade na pesquisa, principalmente quando estas práticas se direcionam à efetivação de políticas públicas. Ao acompanhar equipes que atendem territórios vulneráveis, destacamos aspectos e condições para se pensar os processos urbanos e seu governo. Para isto, primeiro formulamos narrativas do contexto socioambiental desses territórios, em seguida apresentamos contribuições de Walter Benjamin para se pensar o uso dos fragmentos na pesquisa, e então discutimos alguns posicionamentos referentes à força analítica das citações nas pesquisas. Concluímos assinalando os territórios vulneráveis como lugar de produção de saber e de resistência na cidade. Os resultados apontam para a compreensão dos elementos marginalizados como garantidores da cognoscibilidade dos aspectos urbanos das cidades brasileiras, atravessados pelo afeto e pelo caráter dialógico das relações entre diferentes componentes sociais.
\end{abstract}

Palavras-chave: Narrativas, Vulnerabilidade, Território, Experiência.

\section{Vulnerability as a Condition of Knowledge in Social Psychology Research}

\begin{abstract}
In this article we analyze the function and space constructed by narratives and the vulnerability in the ways of building knowledge in social psychology. Production of knowledge has become increasingly displaced from the notion of experience, being recently associated with numerical counting and a presumed ability of the researcher to objectify their field of study. We propose to make the experience of accompanying health teams in the fields of research an element of analysis and construction of a different objectivity in research, especially when these practices are directed to the production and criticism of public policies. In this way, we follow health teams that serve territories in situations of social vulnerability in the Brazilian Northeast region, stressing aspects and conditions to investigate the urban processes and governance of these populations. For such, we first present narratives about the socioenvironmental context of these territories, then some contributions of Walter Benjamin concerning the use of fragments in this paper, only then formulating stances regarding the analytical force of citations in studies. We conclude by indicating vulnerable territories as spaces of production of knowledge and resistance in urban regions. The results point out marginalized elements as ensuring the ability to know urban aspects of Brazilian cities, crossed by the affection and dialogical nature of the relations between different social actors.
\end{abstract}

Keywords: Narratives, Vulnerability, Territory, Experience. 


\title{
La Vulnerabilidad como Condición del Conocimiento en Investigación en Psicología Social
}

\begin{abstract}
Resumen: En este artículo buscamos problematizar la función de las narrativas y las vulnerabilidades en los modos de construir conocimiento en psicología social. La construcción de conocimiento es cada vez más desplazada de la noción de experiencia, y recientemente está asociada a la cuenta numérica y a una supuesta habilidad del investigador en objetivar su campo de estudio. Lo que proponemos es hacer de la experiencia en acompañar a equipos de salud en los campos de investigación un elemento de análisis y de construcción de otra objetividad en la investigación, principalmente cuando estas prácticas se dirigen a la eficacia de las políticas públicas. Acompañamos a equipos de salud que atienden territorios en situación de vulnerabilidad social y señalamos aspectos y condiciones para pensar los procesos urbanos y gubernamentales. Para ello, formulamos en un primer momento narrativas acerca del contexto socioambiental de esos territorios, a continuación presentamos algunas contribuciones de Walter Benjamin para pensar el uso de los fragmentos en la investigación, y después discutimos algunos posicionamientos referentes a la fuerza analítica de las citas en las investigaciones. Como conclusión, destacamos los territorios vulnerables como lugar de producción de saber y de resistencia en la ciudad. Los resultados apuntan a la comprensión de los elementos marginados como garantizadores de la capacidad de conocer los aspectos urbanos de las ciudades brasileñas, atravesados por el afecto y el carácter dialógico de las relaciones entre diferentes actores sociales.
\end{abstract}

Palabras clave: Narrativas, Vulnerabilidad, Territorio, Experiencia.

Ao fazermos da cidade espaço para a produção de conhecimento, estamos situando-nos em um campo de possibilidades diversas. Frequentemente, pesquisadores urbanos da psicologia social, antropologia e sociologia, entre tantas outras disciplinas, encontram nos lugares visitados condições de vulnerabilidade e de violações de direitos que acabam sendo mencionadas ou lembradas na pesquisa. Neste artigo, buscaremos problematizar a função e o lugar erigido pelas narrativas e vulnerabilidades nos modos de construir conhecimento em psicologia social. Tomaremos a denúncia como elemento constitutivo da pesquisa nas cidades; assim, a partir de nossos percursos com pesquisas em territórios vulneráveis, iremos tencioná-la em seu lugar de produção de realidade e de conhecimento. Portanto, este artigo propõe-se a uma discussão metodológica que incorpora aos seus elementos de problematização as narrativas e uma certa concepção de vulnerabilidade.

Partimos do contexto da prática de pesquisa em comunidades e populações que vivem em condições de vulnerabilidade. Escrevemos este artigo a partir do acompanhamento de duas equipes de saúde em uma capital do nordeste brasileiro, as quais assistem pessoas em situação de rua e que vivem em comunidades e territórios pauperizados por processos urbanos. Essas equipes constroem práticas de cuidado que asseguram acesso a direitos básicos como saúde, cultura e educação, além de outros direitos humanos. Durante um período de cerca de oito meses, três vezes na semana, nos deslocávamos de norte a sul na cidade para acompanhar seu trabalho e construir narrativas sobre os processos de urbanização e sua associação às formas com que produzimos memória nas cidades: no sentido benjaminiano, tratamos de uma narrativa que acontecia junto a uma prática, no caso as práticas de cuidado com a saúde alternadas por narrativas concomitantes.

Neste caminho de pesquisa nos deparamos com diversas situações de pauperização e negligência política em relação às condições de vida das pessoas assistidas pelo serviço de saúde do município. Essas condições forneceram narrativas que se aproximavam da denúncia de violações de direitos e começaram a ganhar força nas formas como construímos 
nossa pesquisa. A seguir apontaremos algumas dessas narrativas que constituem modos e processos de urbanização da cidade que acompanhamos e que nos colocaram diante de sua importância para a confecção de visibilidades específicas e aproximações com estas populações.

A denúncia é constituída por nós como elemento de interesse neste artigo pela relevância que ganhou na produção de conhecimento e de realidades quando nos aproximamos de determinados territórios e vulnerabilidades. Deste modo, organizamos o artigo primeiramente descrevendo o contexto dos territórios que seguimos e a produção de narrativas no trabalho de acompanhamento que realizamos. Em seguida, apresentamos os operadores teórico-metodológicos que fazemos uso para pensar a relação entre as figuras do denunciante e do salteador em nossa pesquisa, considerando as contribuições de Walter Benjamin (1987). Por último, retomaremos a produção de visibilidades, conhecimentos e realidades inerentes ao que construímos como vulnerável e débil, para problematizarmos os mapas urbanos de nossas cidades e os processos de urbanização.

\section{Práticas que constroem territórios: aspectos metodológicos}

É comum que nos apoiemos em métodos para proceder na construção de conhecimentos quando fazemos pesquisa. Também é comum se construir problematizações e análises que visem generalizações sobre o tema escolhido para pesquisar. No entanto, alguns aspectos seguem sendo alvo de críticas no procedimento e na construção de metodologias nas ciências humanas. Ao deslocarmo-nos por lugares e ambientes em que há vidas humanas como as nossas, essa pretensa objetividade alcançada pelos métodos recai sobre a habilidade do pesquisador em criar condições de neutralidade que o permitiriam deslocar narrativas para construir condições analíticas favoráveis, o que não é o nosso caso.

Esse jogo de neutralidade e objetividade impede colocar certa experiência como elemento tensionador das metodologias adotadas, bem como uma construção de conhecimento que buscaria neutralizar localidades que situam análises e problematizações (Haraway, 1988). Neste artigo, buscaremos afirmar a força narrativa das análises situadas, destacando a experiência como elemento que nos permite produzir pesquisa. Deste modo, não nos situamos perto da produção de generalizações, ou até mesmo da produção de simples singularidades, mas sim no que Agamben (2009) chama de paradigma, marcado não pela dicotomia particular ou universal, mas pela apresentação de uma singularidade que não se deixa reduzir a nenhum dos termos dessa dicotomia. Isto implica que "a mera exibição do caso paradigmático constitui uma regra tal, que não pode nem ser aplicada nem enunciada" (Agamben, 2009, p. 29, tradução nossa). Neste artigo operamos com a performance da construção paradigmática, destacando a experiência e o sensível na pesquisa, o que constitui este manuscrito como uma narrativa de pesquisa que visa colocar-se em análise: uma narrativa que atua como metaanálise.

Nas relações humanas, incluindo as que ocorrem entre pesquisadores e pesquisados, há uma confecção de experiências que direcionam e constroem modos de conhecer e percorrer territórios. A construção paradigmática apontada por Agamben (2009) desenvolve semelhanças sensíveis entre singularidades por meio de uma operação; diferente de constatá-las simplesmente, confeccionamos aproximações entre particularidades construídas. Ela acontece por meio da relação que produzimos entre uma tipicidade e sua inteligibilidade, por meio da produção de um campo tomado pelo sensível; assim, "a inteligibilidade não precede ao fenômeno, mas está, por assim dizer, ao lado deste" (Agamben, 2009, p. 37). Portanto, não estamos trabalhando pela via da construção de um particular para pensar um universal ou seu contrário (dedução ou indução), mas operando de singularidade a singularidade na construção de conhecimento. Por esta via, pensada como arqueológica pelo autor, torna-se inteligível o presente do pesquisador tanto quanto o passado de seu objeto de estudo.

Nesta direção propomo-nos a revisitar alguns autores e autoras que tomam a vulnerabilidade e o território como problemáticas de seus estudos - bem como a própria noção de narrativas que desenvolvemos neste artigo - a partir de Walter Benjamin, para descrever o que chamamos de fragmentos e apresentar o uso que fazemos deles nos limites que nos são permitidos em um texto de periódico científico. Com esta revisão, tentaremos sublinhar aspectos teórico-metodológicos que nos guiam na construção deste manuscrito.

Guareschi, Reis, Hüning e Bertuzzi (2007) e Reis, Guareschi, Hüning e Azambuja, (2014) retomam o conceito de vulnerabilidade destacando, a partir de objetivos e trabalhos distintos, como esse termo foi 
constituindo um campo de atuação e de pesquisa no campo das ciências psicológicas, por vezes localizando-o em territórios e naturalizando a relação deles com as condições de vulnerabilidade descritas. Para as autoras, esse processo que constrói as vulnerabilidades como objeto de conhecimento acaba por propor intervenções na forma de tutela de determinadas populações e territórios, construindo-os pela ação histórica de exploração e de negação de sua agência política.

Nestes termos, autoras como Ortner (2007), Mahmood (2006) e Das (2007) ressaltam a relevância de pensarmos os processos de agência política de populações e grupos sociais minoritários, provocando-nos a compreender algumas tensões teóricas que separam agência e resistência em termos conceituais. Assim, para Ortner (2007) a agência política é um conceito que nos permite compreender como, apesar dos aspectos de diferença relativos a marcadores como território, gênero, etnia, classe social, entre outros, os sujeitos constroem coletivamente relações políticas de enfrentamento das condições que os submetem. Neste sentido, para pensarmos agência é preciso também ressaltar as redes de solidariedade que compõem esse jogo de ações político-sociais, muitas vezes no cotidiano e nas relações mais corriqueiras. Por isso, ao remetermos à noção de agência para falarmos em vulnerabilidade estamos esgotando esse último termo, de modo a pensá-lo como uma positividade que reúne práticas e condições de sociabilidade relativas a processos de enfrentamento e de resistência.

Deste modo, as autoras anteriormente citadas afirmam que a agência como tal implica também em pensarmos processos de subjetivação, relacionados a tornar-se algo mas também à complexidade dos processos de dessubjetivação, aqueles que dizem respeito a deixar de ser e viver, para ser e viver outro: processos de governamentalidades no território (Ortner, 2007; Mahmood, 2006; Das, 2007). Assim, as autoras que citamos pensam a agência política nessa relação intrínseca entre processos de colaboração e sociabilidade (redes comunitárias, de amigos, família chegada, parentes, professores, padrinhos e assim por diante). Seria nessa direção que o trabalho de pesquisa com narrativas permitiria reconfigurar campos de possibilidades, permitindo outras narrativas e diálogos possíveis para essas existências (Adichie, 2019; Gagnebin, 2012).

De outro modo, o que estamos chamando de narrativas em nosso texto e qual o uso que fazemos delas? Como elaboramos nossas narrativas neste manuscrito? Para pensar sobre estas questões (a nosso ver) teórico-metodologicamente precisamos dar um passo atrás e retomar um distanciamento do que temos como narrativa atualmente.

Jeanne Marie Gagnebin (2009, 2014) retoma dois aspectos importantes para remeter-se ao que Walter Benjamin chama de narrativa. Em primeiro lugar, para Benjamin a narrativa tem um caráter épico (a palavra épico remete também a Bertold Brecht e suas construções em torno das narrativas), logo ela não remete a um sujeito individual e solitário de enunciação. Ao contrário, a narrativa nos moldes benjaminianos extrapola a figura do autor, aquele dos romances, também solitário e interiorizado, para uma coletividade; deste modo, a narrativa seria sempre de uma experiência e - mais do que isso - de uma experiência coletivizada. Em segundo lugar, a narrativa como elemento épico é uma história aberta: ela pode ser incidida e reincida por um tal que conta, podendo atribuir a ela novas características e elementos antes inexistentes (Benjamin, 1966/2017). Neste sentido, como afirma Chimamanda Adichie (2019), "as histórias foram usadas para espoliar e caluniar, mas também podem ser usadas para empoderar e humanizar. Elas podem despedaçar a dignidade de um povo, mas também podem reparar essa dignidade despedaçada" (p. 32).

Deste modo, o uso que fazemos das narrativas neste manuscrito refere-se a estes dois elementos que Gagnebin (2014) retoma. Por vezes, os fragmentos e histórias que trazemos em nossa escrita estão conectados aos outros elementos textuais não como aspectos destacáveis - e, por isso, simplesmente analisáveis do texto -, mas parte da nossa narrativa científica. Tanto quanto os autores e autoras que citamos e compõem esta narrativa escrita, estas histórias que vivenciamos nos campos de pesquisa por onde circulamos durante oito meses garantem legitimidade e tradição às análises que efetivamos. Diferentemente da concepção tácita de pesquisa - para a qual a assimetria, ao apresentarmos uma fala ou narrativa de um sujeito pesquisado, deve ser efetivada por meio de recuos no texto, entre outros recursos textuais - apresentamos uma narrativa inteira nesse artigo (o manuscrito inteiro é uma narrativa) com fragmentos que ao invés de destacarem-se da narrativa geral, incorporam-se a ela. Deste modo, este artigo compõe-se como uma narrativa, ou narrativas.

Os fragmentos que apresentamos remetem a essa performance de escrita que corresponde a uma 
certa oralidade e à construção de uma narrativa científica que remete não a objetificação, mas à produção de agência política. Por isso, o texto propõe-se não simplesmente como um comunicador de resultados e análises de pesquisa; ao contrário, ele opera afetos e sensibilizações capazes de transmitir uma experiência. Retomamos, assim, a ideia de experiência como sendo aquilo que tramita a ciência, o que implica que estas populações com as quais narramos participam da narrativa, mas na condição do sigilo, na medida em que a entrada nessas comunidades perpassa também a construção de narrativas que preservem identidades e autoria.

Se há um sujeito para as narrativas benjaminianas este é o sujeito da debilidade, da fragilidade ou da vulnerabilidade, mas este sujeito é aquele que é capaz de conhecer: é ele o sujeito da cognoscibilidade (Mate, 2011). Deste modo, na contramão das construções que fazem da vulnerabilidade sujeitos para a tutela, em nossa perspectiva ela os torna capazes. São eles que sabem, não aqueles que oprimem e que expropriam:

Se o sujeito do conhecimento é o oprimido que luta ou o que sofre e se rebela, e o objeto de conhecimento é o oco ou vazio dissimulado atrás da contundência compacta do fático, é preciso suspeitar que esse tipo de conhecimento será de difícil acesso (Mate, 2011, p. 18).

Marcada essa dificuldade de acesso a esse saber, ao menos nesse texto, dispomos de armas novas para compor nossas análises, possibilitadas pela construção de narrativas, ao nosso ver fragmentares, outorgadas pela impossibilidade de se construir uma autoria individual e uma análise que nos distancie tanto delas. Coube-nos a produção de uma fragmentariedade composta em nosso texto, diferente das metodologias de produções narrativas (García Fernandéz \& Montenegro Martínez, 2014; Martínez-Gusman \& Montenegro Martínez, 2014; Pérez, Valderrama, \& Alvarez, 2017) que nos inspiram. Estamos no campo das construções que são possíveis a partir da contação de histórias, de narrativas e histórias abertas. Portanto, ao trazermos fragmentos da história de crianças que sofrem racismo, de mulheres que se impõem no contexto de adversidades de vida nas ruas e de processos de colaboração e solidariedade desses ambientes e espaços, por exemplo, estamos indicando a forma como essas histórias nos perpassam, construindo outro campo de objetividades, diferente daquele da neutralidade epistêmica (Balasch \& Montenegro Martínez, 2003).

Heliana Rodrigues $(2004,2010)$ retoma a história oral e a relevância da oralidade para pensar história, memória e narração. Neste sentido, a composição de uma análise também deve voltar-se para sua oralidade, que obedece a diferentes regras de autoria que um texto escrito remete. Ao entrarmos no campo de pesquisa a que nos expedimos aqui, acompanhamos práticas de equipes de saúde e era impossível ligar o gravador ou escrever durante as nossas idas ao campo. Além disso, devido a acordos que condicionavam nossa entrada em campo, não foram permitidos esses procedimentos para resguardar a identidade das pessoas e da comunidade, sendo necessário não somente o sigilo, como também a pura oralidade intranscrevível: a memória passa a ser um aliado para a escrita dessas narrativas e histórias. Portanto, como afirma Rodrigues (2010), a narrativa produzia-se como um intercessor capaz de articular agência em nosso texto; assim, não tratamos da narrativa de quem, mas de qual narrativa é possível: quais narrativas fazem do texto escrito um agenciador para pensar essas vidas e territórios?

Deste modo, as articulações que efetivamos na composição deste manuscrito dizem respeito à construção de continuidades e descontinuidades discursivas; sendo assim, não há em nosso texto um momento em que paramos para narrar. Todo o texto é uma narrativa: uma narrativa escrita que costura com a memória aspectos da cognoscibilidade do mundo construídos junto a essas pessoas e populações. Também não entendemos que, ao menos neste texto, apresentaremos uma narrativa de um sujeito individual para compormos nossas análises, pois atribuímos às narrativas força de citação que compõem conosco uma análise desta experiência. As narrativas não são um momento à parte da apresentação de um texto, elas são parte integrante e itinerantes da formação textual de uma comunicação científica efetivada por pesquisadoras e pesquisadores.

Como tratamos de coletividades, continuaremos a narrar a seguir aspectos do espaço geográfico e histórico dos territórios que acompanhamos, compondo parte de nossa descrição metodológica, referente aos participantes da pesquisa e ao contexto socio-histórico que integram. 


\section{As narrativas estão ao lado dos nossos objetos de estudo: território e história}

Na capital nordestina, em que acompanhamos as equipes de saúde, os processos urbanos são atravessados por duas questões que não podem deixar de ser assinaladas: a) o processo de turistificação urbana; b) os processos de exclusão e de violência direcionados às comunidades periféricas. Tais questões provocam interferências nas formas de organização urbana, delimitando aspectos do governo de territórios considerados vulneráveis. Tornam possíveis também determinadas subjetividades e governos atrelados às formas de narrar e viver em espaços geográficos banhados pelo mar ou por uma orla lagunar nos quais se situam algumas das comunidades que percorremos.

$\mathrm{O}$ turismo e a mercado-alegoria ${ }^{1}$ das cidades brasileiras têm produzido sobre os processos urbanos suas marcas sociais e políticas na vida de comunidades e populações. Isso se dá desde o afastamento das pessoas de ambientes em que viveram durante décadas até a pauperização e favelização progressiva desses territórios, expondo as vidas de uma diversidade de pessoas a condições insalubres de sobrevivência - além da dificuldade permanente de acesso a direitos sociais associados ao enfrentamento das condições de violação de direitos em que vivem. Isto tem sido efetivado a partir de uma lógica de desenvolvimento e progresso urbano que objetiva um embelezamento das cidades (Maricato, 2001; Rolnik, 1997; Santos, 1993).

De modo específico, podemos destacar que o local em que esses milhares de pessoas vivem, em torno do complexo lagunar da cidade, é um lugar de pesca e de criação de animais para subsistência. Este território sofre durante décadas degradação ambiental efetivada pelo despejo de esgoto de diversas cidades que são banhadas pela lagoa, situação que vem sendo alvo da investida do Ministério Público Federal nos últimos anos, buscando-se restabelecer saúde e sustentabilidade ao ambiente do entorno da laguna.

Esta orla lagunar é atualmente regulada por lei estadual que resguarda sua preservação ecológica, incidindo sobre a vida no perímetro em que vivem diversas comunidades com alta rotatividade de pessoas: havia uma entrada e saída de moradores frequente ao longo do ano, como pudemos observar durante o tempo que acompanhamos a equipe de saúde, com uma constante construção e demolição das habitações que os abrigavam. A gestão ambiental deste complexo de moradias e de vidas, que chega a ter $24 \mathrm{~km}$ de extensão, encontra alguns entraves relacionados ao tamanho da orla lagunar e à ausência de saneamento básico e de tratamento de esgoto, que é despejado na lagoa pelos municípios circunvizinhos, incluindo a capital: em suma, a construção sistemática de uma vulnerabilidade e de sua naturalização pelo poder público (Duarte e Cavalcanti, 2012).

A partir daí, a área se consolidou como uma região pobre da cidade, de ocupação irregular e discriminada pela população da cidade, com poucas ações efetivas e eficazes do poder público em benefício dos moradores e do lugar.

A paisagem resultante da Orla Lagunar revela uma apropriação diversificada, que se caracteriza pelo uso do lugar principalmente para a moradia popular. As atividades ligadas ao trabalho e ao lazer de seus moradores consolidaram-se como uma tendência natural do lugar, criando um dinamismo próprio ao local e a seus arredores, apesar da violência e da miséria existentes. Fatos esses que se constituem em barreira, imagem negativa, na percepção do maceioense à Orla Lagunar (Duarte \& Cavalcanti, 2012, p. 17).

Estes aspectos produzem diversos problemas de saúde para a população lagunar que tem a pesca como principal atividade econômica e de subsistência. O território da lagoa é citado em algumas pesquisas como um ambiente de intensa devastação ambiental, devido aos processos de pauperização, degradação e abandono histórico que lhe são destinados, capazes de afetar a saúde do ecossistema e das populações que vivem naquele espaço (Lopes et al., 2017; Tamano, Araujo, Lima, Silva, \& Silva, 2015; Santos \& Sampaio, 2013).

Outro ambiente urbano que acompanhamos durante o mesmo período encontra-se na parte alta da cidade, afastado da orla marítima e lagunar. É um espaço com elevados índices de violência homicida, sendo alvo também da presença ostensiva da força policial (Waiselfisz, 2016). Além disso, pudemos observar que é um dos principais espaços de

\footnotetext{
${ }^{1}$ A composição dessas duas palavras - mercado e alegoria - remete à construção das urbanidades como elemento de desconstrução e fragmentalidade, no sentido de pensar o caráter transitório e histórico do nome mercado que comumente é atribuído ao urbano.
} 
expansão urbana, com a construção de moradias do Minha Casa Minha Vida, programa de habitação do governo federal, bem como a presença de centros comerciais, shopping e de intenso tráfego de carros e pedestres. Esse ambiente é habitado principalmente por trabalhadores que utilizam transporte público, motocicletas e bicicletas para deslocarem-se com a finalidade de trabalhar no centro da cidade, de onde tiram seu sustento por meio do trabalho formal ou informal. É um espaço relativamente distante das praias, e foi ocupado ao longo do século XX por pessoas de outras cidades e estados que vinham para a capital em busca de melhores condições de vida. Ao longo das últimas décadas houve também um crescimento populacional e a intensificação da construção de moradias, pequenos centros comerciais, faculdades e áreas de lazer.

Não podemos deixar de mencionar que os aspectos migratórios e de acolhimento de pessoas de outras localidades é um evento presente nas principais cidades brasileiras, mas também assinalamos que isso ocorre nesta capital pela construção de um estado centrado na monocultura da cana-de-açúcar, atraente a determinado tipo de mão-de-obra precária e incidente sobre formas de habitação e ocupação de terras, aspectos ainda hoje presentes na geografia e história do estado (Silva, 2013; Hüning, 2014).

Nessas regiões da orla lagunar e da parte alta da cidade vivem milhares de famílias com jovens, crianças, adultos e idosos. O perímetro lagunar é alvo das investidas dos governos do estado e do município com projetos de revitalização que planejam reassentamentos involuntários desses núcleos familiares em outras áreas habitacionais da cidade - normalmente a parte alta. Também incidem sobre ele leis de proteção ambiental e políticas de policiamento associadas à guerra ao tráfico de drogas, bem como uma associação - que é feita pelas entidades de segurança pública e pelo restante da sociedade civil, inclusive a mídia - da região aos altos índices de violência desta unidade federativa.

Essa complexidade de questões e de formas de vida nos territórios percorridos da cidade compõem aspectos relevantes das comunidades nas quais andamos junto a equipes de saúde deste município. Continuamos a seguir contando histórias e narrativas que nos colocam frente às questões urbanas pela via da produção de denúncias. As equipes de saúde que acompanhamos são um dispositivo da atenção básica que atende comunidades e pessoas em situação de vulnerabilidade, buscando intervir nas condições de vida para garantir direitos e promover processos de saúde. Além disso, articulam seu trabalho a uma rede de assistência estatal e municipal, a setores parceiros da sociedade civil organizada e, outras vezes, à rede do Sistema Único de Saúde na saúde mental - como pudemos presenciar ao longo do período de acompanhamento das equipes.

\section{Narrativas que contornam comunidades}

No primeiro dia de visita a uma das comunidades, conhecemos três jovens que aparentavam ter entre 16 e 18 anos. Lideravam o território e mostravam-se entusiasmados com a presença de pesquisadores e estudantes da universidade. Era um momento de preparação de uma atividade destinada a crianças e adolescentes, pois havia se aproximado o mês do dia das crianças. Os jovens relatavam a preocupação com atividades culturais que pudessem movimentá-los, além de acudir uma mudança na forma como a comunidade era vista e lembrada pelo restante da cidade - dado que era tantas vezes associada à violência e ao tráfico. Planejávamos atividades com brincadeiras de roda, sacos, bambolês e personagens infantis, fornecendo também alimentação à base de sucos naturais e frutas para aqueles que participassem.

Ao final do dia voltamos para casa e soubemos que, após a saída do local, houve uma abordagem policial que levou à morte de um dos jovens com quem havíamos conversado. Isto fragilizou os envolvidos no planejamento da atividade e foram necessários outros arranjos para que pudéssemos levar adiante a execução da atividade para as crianças. Nessa atividade pudemos nos aproximar da importância daquele dia comemorativo direcionado ao público infanto-juvenil, bem como apercebermo-nos das relações sociais, políticas e institucionais que permeiam a realidade de vida naquele território. De certo modo, a vida curta e as aparentes poucas possibilidades de outras narrativas para suas vidas eram um horizonte que parecia intransponível para quem vivia sobre aquela terra. Havia práticas narrativas e discursivas que os empurravam cedo para a cova. $\mathrm{E}$ era sobre isso que essa primeira visita nos alertava, colocando essa situação como possibilidade para pesquisa e intervenção junto ao serviço de saúde e aos demais parceiros: sutil e irremediavelmente 
éramos convocados a compor outras narrativas e imagens sobre as vidas naqueles territórios.

Como vimos constatando desde o primeiro Mapa da Violência, divulgado em 1998, a principal vítima da violência homicida no Brasil é a juventude. Na faixa de 15 a 29 anos de idade, o crescimento da letalidade violenta foi bem mais intenso do que no resto da população. Vemos. . . que, no conjunto da população, o número de HAF (Homicídios por Arma de Fogo) passou de 6.104, em 1980, para 42.291, em 2014: crescimento de $592,8 \%$. Mas, na faixa jovem, este crescimento foi bem maior: pula de 3.159 HAF, em 1980, para 25.255, em 2014: crescimento de $699,5 \%$ (Waiselfisz, 2016, p. 49).

Naquele instante, e ao longo de nosso percurso de pesquisa, encontrávamos a materialidade das pesquisas e dados estatísticos nacionais na forma com que a cidade se organizava e colocava em questão as relações entre vida e governo em determinados territórios urbanos - ao mesmo tempo em que éramos assaltados pelo constante histórico de negligência pública que se asseverava sobre as formas de existência daquelas pessoas. Como ressaltamos, o processo de pauperização da lagoa e as dificuldades de acesso a direitos que poderiam melhorar suas condições de vida enfatizavam a produção de marginalidade e vulnerabilidade alardeada pela segurança pública, pelos discursos e narrativas midiáticas, bem como por pesquisas de caráter quantitativo e qualitativo. Ao invés de garantirem condições de enfrentamento a essa condição, incentivavam a expulsão de moradores daqueles espaços urbanos e a ação truculenta da polícia.

Na parte alta da cidade não deixamos de acompanhar histórias que tinham o mesmo cunho de produção e intensificação de negligências sociais. Condições que estavam direcionadas a mulheres - devido à violência de gênero -, a homens e mulheres que faziam uso de álcool em situação de rua, e a tantas outras pessoas que, desassistidas em seus direitos, acabavam por chegar aos serviços em condições de fragilização dos vínculos familiares e comunitários difíceis de se reverter. Essas histórias e narrativas compunham um cenário de práticas fragmentado em que as vidas e histórias que encontramos funcionam como citações em nossas pesquisas: aquelas citações que nos obrigam a pensar e, por diversas vezes, questionar as práticas corriqueiras de pesquisa e de cuidado.

Encontrávamo-nos com histórias de sobrevivência naturalizadas pelas condições políticas e econômicas do estado. Havia tanto uma associação dos seus modos de vida às maneiras como adoeciam e morriam quanto uma responsabilização e culpabilização dessas pessoas pela produção de sua vulnerabilidade. Isto ocorria, por exemplo, ao serem recusados em serviços públicos de saúde devido à condição de rua em que viviam e, em alguns casos, por serem usuários de álcool ou outras drogas, muitas vezes somente admitidos no serviço quando acompanhados de alguém da equipe de saúde.

Ao longo de meses pudemos participar de ambientes em que os laços sociais e afetivos nas situações de rua eram fatores visíveis para a qualidade de vida dessas pessoas. Embora houvesse um cenário marcado pela negligência do poder público e pela dificuldade de acesso e garantia de direitos para essa população, estabeleceram nos territórios em que viviam relações de cooperação e apoio mútuo para lidar com os infortúnios, a partir de suas possibilidades e condições.

Durante atividades com jovens da comunidade na orla lagunar, em diversos momentos visualizamos a construção de práticas e ações que iam nessa direção. Em uma atividade de estágio desenvolvida por estudantes de Psicologia, foram realizadas rodas de conversa sobre diversas temáticas escolhidas pelos jovens ao longo dos encontros. Nessas rodas as estudantes traziam um lanche com alguns alimentos e em outros dias pudemos compartilhar de uma alimentação preparada pelos jovens da comunidade. Prepararam peixes para nossa refeição, algo que os alimentava diariamente e era fonte de sustento para parte significativa das pessoas que residem naquele território banhado pela lagoa.

Ao longo das rodas de conversa com os jovens, ouvimos e participamos de narrativas que causaram intensas emoções em quem estava ali. Foram frequentes, por exemplo, relatos de crianças sobre comentários a respeito de seus cabelos, de que não penteavam, que tinha uma aparência de descuido ou que deveria ser cortado - comentários que assaltam essas crianças nas ruas e nas escolas e que de forma significativa provocavam reações de apoio daquelas que os ouviram durante os encontros do grupo, despertando silêncios e debates acalorados sobre o enfrentamento de situações como essas por parte do grupo de jovens da comunidade. 
Em outra situação, na parte alta da cidade, acompanhávamos um casal de idosos que vivia em situação de rua. O lugar que habitavam era comumente ocupado por amigos e pessoas com quem compartilhavam histórias, experiências, utensílios, comida, cigarros e bebidas. Nas vezes em que estivemos juntos, a senhora, de aproximadamente sessenta anos, costumava nos acolher com abraços e com seus sonhos, quando conseguia dormir: ela dormia embaixo de um carro que estava sem condições de uso, lugar quente e que a protegia da chuva. Falava-nos dos seus receios com as doenças que tomavam seu corpo, dos procedimentos médicos invasivos que a deixavam preocupada e indicavam seu adoecimento, além de tantos outros relatos feitos durante as abordagens da equipe de saúde. Seu esposo por perto acompanhava as histórias. Os amigos que compartilhavam dos momentos apoiavam uns aos outros, cantavam e davam leveza a cada relato e medo mencionado. Não que houvesse ausência de conflitos, como em todas as convivências entre pessoas: em certos momentos era necessário que aquela senhora pedisse e impusesse respeito, mas nada que destoasse do pedido dela, que era rapidamente acatado pelos amigos. Essas conversas aconteciam na rua sendo interrompidas pela passagem de carros rente aos nossos corpos e pelo som alto de uma loja de som localizada na esquina. Nesse ambiente ocorriam os procedimentos de cuidado da equipe, além das possibilidades de afeto e de amizade com esses homens e mulheres.

Estas narrativas têm uma importância imensa nos modos como visibilizamos informações e dados sobre algumas vidas. Em alguns momentos as pesquisas deixam de contar algumas histórias e construir certas narrativas sem as quais as práticas de pesquisa não seriam possíveis, nem tampouco seria possível o desenvolvimento de práticas de cuidado e proteção dessas pessoas. A produção de afetos é o ponto de partida destas relações urbanas, principalmente quanto ao estabelecimento de serviços, programas e políticas públicas com essa população. Tornar visível a produção humana de relações e afetos é aspecto fundamental de nossas atividades de pesquisa junto a estas populações, escapando dos números como elemento de revelação de uma realidade objetiva e apostando nas microrrelações como espaço para elaboração de outros pensamentos sobre a cidade e as vidas (Moraes \& Arendt, 2013; Martin, Spink, \& Pereira, 2018).
Neste sentido, conforme Vinciane Despret (2011), cabe-nos a construção de visibilidade dos afetos para a construção de políticas de pesquisa, mas também de existência, na forma em que possibilitam políticas públicas para essas populações, construindo - dessa maneira - condições para sua participação efetiva nos modos de propô-las, sendo necessário atentarmo-nos para esses aspectos que costumeiramente abandonamos em nossas pesquisas.

A partir daqui a denúncia que anunciamos inicialmente neste artigo diz respeito às formas como tomamos essas vidas como objeto de governo, de saberes e de relações de poder a partir de nossas práticas de produção de conhecimentos. As vidas, que narramos em diferentes momentos e com as quais convivemos, reclamam outras práticas legitimadoras de sua existência, mas também sua capacidade de luta e de resistência no cotidiano da vida comunitária e urbana. Ao retomarmos aspectos estruturais da cidade e do estado em que vivem como elementos que determinariam e subordinariam suas vidas, também apontamos relações de afeto, amizade e cooperação que tornam o cuidado possíveis. Certamente essas narrativas dinamizam o repertório da pesquisa ao apresentarem-se como fragmentos e citações incorporados aos relatos de pesquisa, dialogando com as análises e discussões dos autores que nos acompanham, e obrigando-nos a revisitar práticas, questões e objetivos inicialmente assentados em um estudo.

Apresentamos essas questões para que possamos visibilizar o terreno de práticas e de territorialidades que as narrativas provocam, constituindo campos de experiência e de vida. Deste modo, seguimos para nossos operadores teóricos como contexto analítico das práticas narrativas que desenvolvemos e apresentamos anteriormente. Retomaremos algumas contribuições de Walter Benjamin para partirmos da noção de denúncia ou do denunciante, como personagem de pesquisas em psicologia social, para a figura do salteador, que articula, por meio dos fragmentos e citações, condições para a produção de conhecimento.

\section{Dos números às letras: operando conceitos}

Nos relatos que acompanhamos com populações em situação de rua e vulnerabilidade social, ocorre normalmente uma fragmentação e certa imprecisão na forma como são contados. No entanto, essas brevidades, estilhaços e cacos narrativos compõem 
não simplesmente uma falha de narração ou um defeito cognitivo, mas uma performance da realidade. Correspondem, assim, a uma forma como a realidade é produzida, apresentada e presentificada para essas pessoas, em uma relação de poder que acomete seus corpos e suas subjetivações.

A partir daqui nos ocuparemos de pensar aspectos das narrativas periféricas e do que chamamos de denúncia efetivando alguns deslocamentos necessários, bem como o que essas narrativas operam em termos da produção de conhecimento em psicologia social quando nos vemos em comunidades e territórios urbanos pauperizados por uma lógica de progresso neoliberal.

Walter Benjamin, em seu projeto do livro Passagens (1982/2018) e também em outras obras, como Rua de Mão Única e Infância em Berlim por volta de 1900 (2013, 1987), utiliza-se de fragmentos e anotações breves sobre as cidades, memórias de infância e outros recursos que se assemelham para, entre tantas questões, construir um pensamento andarilho sobre as cidades de seu tempo. Este autor judeu, perseguido pelo nazismo, andava pelas ruas parisienses com cadernos de anotações nos quais registrava frases soltas que ouvia, textos de publicidade que encontrava nas avenidas, além de uma variedade de pedaços de discursos e de narrativas que retomava em seus textos. Ao trazer para a cena do texto esses recortes e fragmentações, Benjamin exibe e cria condições para uma desnaturalização das questões dadas, operando seu pensamento.

Tal recurso metodológico, que nos inspirou, levou-lhe a construir um conhecimento andarilho pela cidade de Paris no período da Primeira Guerra Mundial, sendo relevante para pensarmos algumas relações de governo direcionadas ao que tornamos excesso (dispêndio/resto) no território urbano de nossas cidades. Para Muricy (2009) esse trabalho sobre os fragmentos busca a reconstrução de um mundo a partir das ruínas de um passado perdido. Com a montagem dos fragmentos, Benjamin buscou tornar esse mundo visível em um conhecimento que julgava capaz de elucidar o passado, tornando o presente inteligível. Esses recursos, que atuam principalmente pela força da rememoração e da memória, ao invés de fomentar a busca de um passado ou de uma subjetividade daquele que narra, cruzam a vida pessoal e a história, apresentando o que ele chama de um conhecimento sem mediações sobre o mundo - uma memória que se apresentava para Walter Benjamin na percepção infantil do mundo, incrustada nas ruas, monumentos e praças, bem como nos objetos de seu tempo.

Para este autor o pensamento e a escrita funcionam de modo inseparáveis. Apresentando-se de imediato por meio de imagens, ganham força de verdade sobre o presente, elaborando uma crítica de nossos costumes, verdades e de nossa época. Essa fragmentação vem ao encontro de uma performatividade histórica que toma as cidades e a vida urbana a partir de uma crítica à modernidade e à ascensão do capitalismo industrial na Europa, cujas características fundamentais seriam: a divisão do trabalho e a segmentação das fases de produção com a finalidade de fabricar produtos em série para o consumo; as mudanças na arquitetura das cidades com a chegada do vidro e do ferro; uma produção constante de interiores nas engenharias e arquiteturas das casas; a mudança nos estilos literários com os romances de folhetim em jornais; e, também, a emergência de narrativas psicológicas com ênfase na subjetividade interiorizada dos romances emergentes, incluindo uma leitura silenciosa e subjetivizante até então pouco frequente. Estes elementos fazem o autor construir uma análise filosófica-literária da modernidade, propondo-se a retomar essa fragmentação como referência metodológica na formulação de seu pensamento, principalmente a partir de meados da década de 1920 e intensificando-se nos anos seguintes.

Atualmente, com a intensificação dos processos urbanos e econômicos, as cidades produzem por meio de uma linguagem publicitária os fragmentos narrativos e de discurso que governam nossos desejos. Do mesmo modo, os processos urbanos produziram as chamadas artes e manifestações de rua que são características das cidades. Vemos o aparecimento de uma arte periférica que assume proporções significativas para a proliferação de narrativas silenciadas na história de algumas populações. O hip-hop, com o rap, pichações e grafites, a literatura marginal, o cinema e o teatro das periferias constituem cada um a seu modo os fragmentos como referência para seus trabalhos.

No Brasil esses elementos artísticos imprimem uma força política de reivindicação social, ao mesmo tempo em que produzem memória de fatos e acontecimentos do cotidiano de homens e mulheres das periferias, construindo um corpo e uma objetividade para os fragmentos históricos do presente. Essa fragmentação refaz um percurso que deve ser assinalado, 
pois aponta uma série de questões políticas, sociais e econômicas às quais nos submetemos diariamente.

As narrativas contemporâneas, que encontramos na periferia, apresentam-nos um corpo governado aos pedaços, como o Leviatã utilizado por Thomas Hobbes para fundar uma das teorias modernas da origem do Estado. As histórias contadas pela memória de cacos e ruínas formam uma corporeidade política das minorias/maiorias, relativas a negros, pobres e periféricos de diferentes gêneros, capaz de torná-los visíveis, apresentando o insuportável por meio da monstruosidade que possibilita as práticas que violam e exploram suas vidas (Mbembe, 2018).

Tal monstruosidade, concretizada pela história e pela violência simbólica e efetiva a que essas populações são submetidas, imprime uma formação narrativa que exaure as palavras e a memória destes locais, restando somente indícios e sinais rachados de uma complexidade histórica inexprimível. Não é de hoje que conhecemos os transtornos pós-traumáticos e sua referência aos problemas de linguagem e de memória: ex-soldados combatentes em condições de exaustão física e psicológica até o fim de suas vidas, com espasmos de recordações das situações de guerra e em alguns casos uma mudez absoluta ao retornarem para casa; assim como as condições de desnutrição e violência nos campos de concentração que deixaram suas marcas nas vidas e corpos dessas pessoas, principalmente na linguagem e em sua capacidade mnemônica (Agambem, 2008). Não é de se estranhar que as lembranças - de violências e de violações de direitos históricas - de uma parcela significativa da população brasileira constituída principalmente por negros, pobres e periféricos apresentem suas histórias aos pedaços, como uma memória social partida que ganha importância e contorno justamente no encontro entre o pessoal e a história política e social do país.

Essa perda sistemática de uma memória escrita e oficial que atribui às narrativas periféricas de negros e pobres uma legitimidade apenas oral, principalmente por meio da música e dos costumes, reformula condições a partir das quais o sócio-político torna-se decisivo para a formulação de realidades e de conhecimento. Deste modo, ainda que as narrativas e histórias que apresentamos inicialmente indiquem uma subjetividade ou aspectos de um modo de ser sujeito, o social, a política, a economia e a história são fundamentais para a compreensão e problematização do presente, sendo aliados para a construção de conhecimentos e atualização da realidade nos percursos de pesquisa e experiências de vida.

Nos fragmentos e cacos de memória que encontramos durante o acompanhamento das equipes de saúde na capital nordestina, há uma força tamanha que o encontro deles com a história possibilita a composição de outros horizontes narrativos, capazes de orientar práticas profissionais e de pesquisa. Por exemplo, inicialmente ao entrarmos nas comunidades estávamos planejando a construção da pesquisa por meio da produção de imagens com uso de fotografias e vídeos; no entanto, a conversa com os jovens líderes da comunidade, descrita inicialmente, proporcionou outros modos de conduzir e construir a pesquisa, redirecionando-a para pensar a produção de vulnerabilidade por meio das relações entre memória e urbanização.

A questão que apresentamos diz respeito ao que Benjamin (1987) afirma sobre a força das citações em seu trabalho: "as citações em meu trabalho são salteadores no caminho, que irrompem armados e roubam ao passeante a convicção" (p. 61). Essa formulação do autor auxilia-nos quanto ao deslocamento do lugar da denúncia para o que podemos assinalar como sendo o do salteador, aquele que no meio do percurso rouba-nos a esperança e as certezas, fazendo-nos alterar rotinas, procedimentos e convicções. Ao transformar os acontecimentos cotidianos em citações, fazendo-os procederem como elementos de uma composição discursiva capaz de mobilizar outros pensamentos e problematizações, produzimos nestes territórios movimentos que retiram da rotina determinados enunciados que recaem sobre essas pessoas e territórios.

Nesta operação podemos visibilizar a produção de vulnerabilidade inerente aos modos como construímos narrativas nestes espaços urbanos - ao mesmo tempo em que, ao não simplesmente ignorar os números mas incidir sobre as palavras e as vidas a que eles remetem, criamos condições para o desenvolvimento de outras visibilidades e afetos não-oficiais e não-registrados pelos discursos hegemônicos. Essas visibilidades específicas constroem ferramentas capazes de interferência na realidade local, além de nos proporcionar condições de conhecimento quando deslocamos esses territórios para pensá-los como lugares de produção de verdades sobre a cidade.

Esse mundo fragmentado das denúncias tornadas em citações apresenta-nos universos inacabados 
que carecem de intervenções. Essa segmentação discursiva e narrativa ganha conformidade à medida em que podemos explorá-la para construir outros pensamentos na cidade. Admiti-las como contra-narrativas que assumem a função não somente de oposição e guerrilha, mas também de exprimir uma simples existência, faz-nos recolocar a pesquisa em um território de produção de verdades nas cidades, no qual as vulnerabilidades existem como condição para negligenciar um arsenal de práticas de resistência urbana.

Estes elementos constituem sobre os territórios vulneráveis uma forma de compreensão que reformula a fragilidade que lhe é atribuída pelos discursos oficiais da cidade. Diferentemente de afirmar esses espaços como locais ideais, assinalamos que formulam conhecimento e uma tradição de resistência que a cidade busca apagar e silenciar de seu repertório existencial. No entanto, atentarmos para suas tradições, costumes, economia, cultura e gestão da vida nos possibilitaria construir alternativas à lógica de mercado e negócio que subordinam as cidades. Para além de uma narrativa de segurança pública que destina esses territórios à ação policial truculenta, podemos pensar como constroem vida e sobrevivência de modo a produzir enfrentamentos efetivos das condições de vulnerabilidade que tornam algumas práticas de urbanização possíveis. É à constituição histórica e geográfica das cidades que nos remetemos, mas também aos modos como essas pessoas tornam possível sua existência frente às adversidades que as submetem. De outro modo, como nos assinalaram os jovens no nosso primeiro dia na comunidade, é sobre afetos e memória que produzimos conhecimento e intervenções nesses territórios, seja para fazer viver ou para fazer morrer.

\section{Excessos urbanos na produção de vida e de conhecimento}

Em alguns momentos pode parecer imprescindível nos questionarmos sobre o que torna esses territórios atrativos à vida, ou mesmo quais as motivações pessoais e subjetivas que os fazem habitados. No entanto, estas questões são modos de nos endereçarmos a causas e efeitos que estão atrelados tanto a uma ideia de construção individual de um desejo, quanto a uma sociologização forçada de aspectos inscritos em uma relação de poder atravessada por múltiplos fatores, alguns deles apresentados anteriormente.
Tais perguntas forçam uma aparência de verdade, mas espetacularizam a vida e os territórios em que essas pessoas vivem, impedindo que possamos investir nesses espaços urbanos considerando-os lugares em que a vida humana seja possível não submetida a uma lógica de mercado. As narrativas que trouxemos no início deste artigo formulam um território tomado pela produção de sobrevivência em que é possível encontrar outros usos para os excessos que o tornam possível. A pluralidade de histórias que encontramos invisibilizadas pela imagem de violência, que se multiplica nos discursos midiáticos e de segurança pública da cidade, guardam um saber e uma memória histórica indispensável para as políticas de urbanização e de pesquisa nesses territórios. As questões que apontamos dizem respeito não a uma relação de causa e efeito simplesmente, mas à construção de alternativas aos discursos hegemônicos que encerram essas vidas em uma fragilidade e vulnerabilidade imobilizadora das suas capacidades e histórias, produzindo entre outras coisas sua tutela.

Neste aspecto, retomamos as contribuições benjaminianas a partir das quais nos é assinalada a força e a potência da fragilidade e da debilidade na produção de conhecimento. A partir dessa perspectiva, os segmentos, os cacos, os fragmentos e tudo o mais que seria dispensado pelo progresso constituem condições de produção de verdade: haveria no despedaçado, naquilo que seriam os excessos da ordem do progresso, condições de inteligibilidade do mundo. Este aspecto torna-se um elemento para o pensamento da cidade $\mathrm{e}$ mesmo para as práticas de pesquisa, uma vez que sistematicamente a vida urbana tem se ocupado em produzir excessos e governá-los arbitrariamente.

Para Benjamin (1987) o pensamento não ocorre em uma cadeia lógica e racional coerente, mas por meio de fragmentos e ausências com espasmos, silêncios e brechas. Segundo ele, o pensamento seria semelhante a um relampejo no céu, que exigiria do pesquisador atenção e um despertar para a vida que ocorre em seu entorno. O pensamento ocorreria como um golpe, em uma rapidez e imediaticidade que já não estamos habituados a perceber. E é para isto que nos alerta: $o$ aspecto fugaz e decisivo do pensamento. Ao mesmo tempo, podemos dizer que esse pensar não ocorre simplesmente na mente do pesquisador, mas nos eventos e acontecimentos que o cercam, na história dos objetos e nas narrativas que o exigem: o mundo e as coisas do mundo possuem uma inteligibilidade. 
Portanto, é a debilidade que faz pensar. Seria essa fragilidade que apresentaria condições de estranhar o mundo, condições de outras políticas. Nesta série de questões a fraqueza seria o que constitui a verdade e criação do pensamento. A falta de sustança apontada tantas vezes nas vidas em territórios vulneráveis seria o que mobiliza um campo de verdades, desarticulando-o. Mate (2011) afirma: "o lúmpen, o que sofre, o oprimido, o que está em perigo, mas que luta, protesta, se indigna. É esse sujeito que pode conhecer o que os demais (o que oprime ou manda ou passa ao largo) não podem conhecer" (p. 22).

Deste modo, temos um princípio de inteligibilidade que, ao contrário de reificar estes territórios, os propõem como espaços de produção de saberes nas cidades. Seus fragmentos e narrativas funcionam enquanto citações que "em vez de confirmar o que já sabemos, destroem os tópicos, as verdades estabelecidas do autor, obrigando-nos a pensar de novo" (Mate, 2011, p. 120). Esse caráter irremediável das histórias contadas e ouvidas em um campo de pesquisa são fundamentais na produção de pensamento na cidade.

O governo dos excessos - compreendidos nesse texto como os territórios vulneráveis, associados ao que George Bataille escreveu sobre economia e dispêndio - passa também por uma política narrativa. Os modos de narrar e contar esses territórios estão relacionados à produção de afetos que direcionam formas de governo de suas vidas. Ocupar-nos com estas políticas de narração recoloca a questão do governo dessas populações não pela dimensão do progresso e da aceleração, mas pela efetivação de uma inseparabilidade entre fala e ação, escrita e política.

Esse mundo das denúncias, das histórias incompletas, da insuficiência narrativa, dos fatos e afetos, exibe um outro momento de formação narrativa com o qual é possível construir uma crítica e pensamento sobre os governos e as relações de poder, mas também sobre a produção de invisibilidades, vulnerabilidades e negligência. Aspectos esses que necessitam ser integrados e ganham força ao comporem análises, e ao efetivar e integrar eixos narrativos e analíticos em nossas pesquisas e estudos.

\section{Considerações finais}

Ao longo de décadas os territórios vulneráveis são tematizados por discursos midiáticos e de segurança pública como espaços de disseminação de violência e de vícios para as cidades (Coimbra, 2001). Estes discursos produzem uma gestão desses territórios a partir de uma lógica de policiamento e de deslegitimação de suas formações discursivas. Quando adentramos nestes ambientes podemos identificar aspectos e questões complexas dessa relação estabelecida pelos números e estatísticas com a vida vivida por essas pessoas. Há uma historicidade impossível de ser desconsiderada, como também uma formação narrativa dessas pessoas que carece ser colocada no campo das análises sociais e políticas contemporâneas.

É sobre um giro narrativo que nos referimos ao longo de nossas análises. Momento em que, ao invés de afirmar a legitimidade dos discursos oficiais, torna-se necessário ampliar o alcance das análises locais e periféricas sobre sua própria formação e gestão urbana. Embora a denúncia seja um recurso que formula condições de narração nesses espaços urbanos, a produção de conhecimentos toma-a como elemento de disposição analítica de relações de poder e de formulação de uma vulnerabilidade e negligência que aparentam ser indispensáveis para a lógica do progresso urbano.

Por fim, assinalamos que estes territórios compõem com fragmentos, silêncios/barulhos e lacunas condições de interrogação e estranhamento da vida urbana e dos projetos de urbanização que os relegam para os excessos urbanos e para um governo deliberadamente arbitrário. Do mesmo modo, assinalamos que a produção de conhecimento e de realidades, indissociáveis nestes territórios urbanos, ocorrem por meio da formulação de afetos e visibilidades específicas de questões históricas que se arrastam no cotidiano da vida das cidades brasileiras em uma herança escravagista importante de ser mencionada, pois permanece construindo sobre a vida periférica uma corporeidade narrativa e discursiva que a coloca à mercê dos excessos de governo e da gestão violenta. Estes são aspectos que nos convidam a pensar não somente o lugar de fala dos nossos colaboradores nas pesquisas, como também a construção de aproximações e metodologias que afirmam uma neutralidade e verticalidade do pesquisador nesses territórios. É, portanto, como enfrentamento aos modos de relação hegemonicamente construídos que propomos a atenção para os fragmentos de citações que se produzem nos territórios vulneráveis urbanos como estratégia de produção de conhecimentos. 


\section{Referências}

Adichie, C. N. (2019). O perigo de uma história única (1a ed.). São Paulo, SP: Companhia das Letras.

Agamben, G. (2008). O que resta de Auschwitz: O arquivo e a testemunha (Homo Sacer III). São Paulo, SP: Boitempo.

Agamben, G. (2009). Signatura rerum: Sobre el método (1a ed.). Buenos Aires: Adriana Hidalgo.

Balasch, M., \& Montenegro Martínez, M. (2003). Una propuesta metodológica desde la epistemología de los conocimientos situados: Las producciones narrativas. Encuentros en Psicología Social, 1(3), 44-48.

Benjamin, W. (2017). Ensaios sobre Brecht. São Paulo: Boitempo. (Trabalho original publicado em 1966)

Benjamin, W. (2018). Passagens (Vols. I, II e III). Belo Horizonte: Editora UFMG. (Trabalho original publicado em 1982)

Benjamin, W. (2013). Rua de mão única: Infância berlinense: 1900 (João Barrente, trad.). Belo Horizonte: Autêntica Editora.

Benjamin, W. (1987). Obras escolhidas II: Rua de mão única. São Paulo, SP: Editora Brasiliense.

Coimbra, C. (2001). Operação Rio: O mito das classes perigosas: Um estudo sobre a violência urbana, a mídia impressa e os discursos de segurança pública. Rio de Janeiro, RJ: Oficina do Autor; Niterói, RJ: Intertexto.

Das, V. (2007). The act of witnessing: Violence, gender and subjectivity. In Life and Words (pp. 59-78). Berkeley: University of California Press.

Despret, V. (2011). As ciências da emoção estão impregnadas de política? Catherine Lutz e a questão do gênero das emoções. Fractal: Revista de Psicologia, 23(1), 29-42.

Duarte, R. O., \& Cavalcanti, V. R. (2012, novembro). Orla lagunar de Maceió: Uma paisagem em movimento. Artigo apresentado no XXIV Congresso Panamericano de Arquitetos, Maceió, AL.

Gagnebin, J. M. (2009). Lembrar escrever esquecer. São Paulo, SP: Editora 34.

Gagnebin, J. M. (2012). Prefácio: Walter Benjamin ou a história aberta. In W. Benjamin, Magia e técnica, arte e política: Ensaios sobre literatura e história da cultura (S. P. Rouanet, trad., 8a ed. rev., pp. 7-19). São Paulo, SP: Brasiliense.

Gagnebin, J. M. (2014). Limiar, aura e rememoração: Ensaios sobre Walter Benjamin. São Paulo, SP: Editora 34.

García Fernandéz, N., \& Montenegro Martínez, M. (2014). Re/pensar las producciones narrativas como propuesta metodológica feminista: Experiencias de investigación en torno al amor romántico. Athenea Digital, 14(4), 63-88.

Guareschi, N. M. F., Reis, C. D., Huning, S. M., \& Bertuzzi, L. D. (2007). Intervenção na condição de vulnerabilidade social: Um estudo sobre a produção de sentidos com adolescentes do programa do trabalho educativo. Estudos e Pesquisas em Psicologia, 7(1), 17-27. http://pepsic.bvsalud.org/scielo. php?script=sci_arttext\&pid=S1808-42812007000100003\&lng=pt\&tlng=pt.

Haraway, D. (1988). Situated knowledges: The science question in feminism and the privilege of partial perspective. Feminist Studies, 14(3), 575-599. https://doi.org/10.2307/3178066

Hüning, S. M. (2014). Encontros e confrontos entre a vida e o direito. Psicologia em Estudo, 19(3), 491-501. http:// dx.doi.org/10.1590/1413-73722229312

Lopes, D. V. S., Silva, D. E., Silva, F. M. S., Paraíso, L. A., Soares, T. L., \& Souza, M. C. B. (2017). Áreas de Proteção Ambiental (APA) de Conservação da Bacia do CELMM. Cadernos de Graduação, Ciências exatas e tecnológicas, 4(2), 73-88. https://periodicos.set.edu.br/fitsexatas/article/view/5203

Mahmood, S. (2006). Teoria feminista, agência e sujeito liberatório: Algumas reflexões sobre o revivalismo islâmico no Egipto. Etnográfica, 10(1), 121-158.

Maricato, E. (2001). Brasil, cidades: Alternativas para crise urbana. Petrópolis, RJ: Vozes.

Martin, D., Spink, M. J., \& Pereira, P. P. G. (2018). Corpos múltiplos, ontologias políticas e a lógica do cuidado: Uma entrevista com Annemarie Mol. Interface - Comunicação, Saúde, Educação, 22(64), $295-305$. https:/ /dx.doi.org/10.1590/1807-57622017.0171

Martínez-Guzmán, A., \& Montenegro Martínez, M. (2014). La producción de narrativas como herramienta de investigación y acción sobre el dispositivo de sexo/género: Construyendo nuevos relatos. Quaderns de Psicologia, 16(1), 111-125. 
Mate, R. (2011). Meia-noite na história: Comentários às teses de Walter Benjamin "Sobre o conceito de história". São Leopoldo, RS: Ed. Unisinos.

Mbembe, A. (2018). Crítica da razão negra. São Paulo, SP: n-1 edições. (Trabalho original publicado em 2013).

Moraes, M. O., \& Arendt, R. J. J. (2013). Contribuições das investigações de Annemarie Mol para a psicologia social. Psicologia em Estudo, 18(2), 313-321. https://dx.doi.org/10.1590/S1413-73722013000200012

Muricy, K. (2009). Alegorias da dialética: Imagem e pensamento em Walter Benjamin. Rio de Janeiro, RJ: Nau.

Ortner, S. (2007). Poder e Projetos: reflexões sobre a agência. In M. P. Grossi, C. Eckert, \& P. Fry (Orgs.), Conferências e diálogos: Saberes e práticas antropológicas (pp. 45-80). Blumenau, SC: Nova Letra.

Pérez, L., Valderrama, C., \& Alvarez, C. (2017) Las producciones narrativas como metodología de investigación feminista en psicología social crítica:Tensiones y desafíos. Individuo y Sociedad, 16(2), 20-32. https://dx.doi.org/10.5027/ psicoperspectivas-Vol16-Issue2-fulltext-956

Reis, C., Guareschi, N. M. F., Hüning, S. M., \& Azambuja, M. A. (2014). A produção do conhecimento sobre risco e vulnerabilidade social como sustentação das práticas em políticas públicas. Estudos de Psicologia, 31(4), 583-593. https:// dx.doi.org/10.1590/0103-166X2014000400012

Rodrigues, H. B. C. (2004). O homem sem qualidades: História oral, memória e modos de subjetivação. Estudos $e$ Pesquisas em Psicologia, 4(2), 24-46.

Rodrigues, H. B. C. (2010). A história oral como intercessor: Em favor de uma dessujeição metodológica. Estudose Pesquisas em Psicologia, 10(1), 190-203.

Rolnik, R. (1997). A cidade e a lei: Legislação, política urbana e territórios na cidade de São Paulo. São Paulo, SP: Studio Nobel.

Santos, E. C., \& Sampaio, C. L. S. (2013). A pesca artesanal na comunidade de Fernão Velho, Maceió (Alagoas, Brasil): De tradicional a marginal. Revista da Gestão Costeira Integrada, 13(4), 513-524.

Santos, M. (1993). A urbanização brasileira. São Paulo, SP: Hucitec.

Silva, W. V. N. (2013). Entre ruas que subjetivam, registros do governo da vida e da morte na cidade. (Dissertação de Mestrado), Universidade Federal de Alagoas, Maceió, AL.

Tamano, L. T. O., Araujo, D. M., Lima, B. B. C., Silva, F. N. F., \& Silva, J. (2015). Socioeconomia e saúde dos pescadores de Mytella falcata da Lagoa Mundaú, Maceió-AL. Boletim do Museu Paraense Emílio Goeldi. Ciências Humanas, 10(3), 699-710. http://dx.doi.org/10.1590/1981-81222015000300011

Waiselfisz, J. J. (2016). Mapa da violência 2016: Homicídios por armas de fogo no Brasil. São Paulo, SP: Flacso Brasil.

Wanderson Vilton Nunes

Docente do Programa de Pós-Graduação em Psicologia do Departamento de Psicologia da Universidade Federal de Pernambuco (UFPE), Recife - PE. Brasil.

E-mail: wandersonvilton@gmail.com

(1) https://orcid.org/0000-0003-2396-9933

\section{Simone Maria Hüning}

Docente do Programa de Pós-Graduação em Psicologia do Instituto de Psicologia da Universidade Federal de Alagoas (UFAL), Maceió - AL. Brasil.

E-mail: simone.huning@ip.ufal.br

(1) https://orcid.org/0000-0001-8080-7733

Neuza Guareschi

Docente do Programa de Pós-Graduação em Psicologia Social e Institucional do Instituto de Psicologia da Universidade Federal do Rio Grande do Sul (UFRGS), Porto Alegre - RS. Brasil.

E-mail: nmguares@gmail.com

(1) https://orcid.org/0000-0001-5892-188X 
Endereço para envio de correspondência:

Universidade Federal de Pernambuco, Centro de Filosofia e Ciências Humanas, Departamento de Psicologia. Av. Prof. Moraes Rego, 1235, Cidade Universitária, Iputinga. CEP: 50670-901. Recife - PE. Brasil.

Recebido 24/08/2018

Aceito 02/03/2020

Received 24/08/2018

Approved 02/03/2020

Recibido 24/08/2018

Aceptado 02/03/2020

Como citar: Silva, W.V. N., Hüning, S. M., \& Guareschi, N. (2020). Da Vulnerabilidade como Condição de Saber nas Pesquisas em Psicologia Social. Psicologia: Ciência e Profissão, 40, 1-16. https://doi.org/10.1590/1982-3703003213073

How to cite: Silva, W. V. N., Hüning, S. M., \& Guareschi, N. (2020). Vulnerability as a Condition of Knowledge in Social Psychology Research. Psicologia: Ciência e Profissão, 40, 1-16. https://doi.org/10.1590/1982-3703003213073

Cómo citar: Silva, W. V. N., Hüning, S. M., \& Guareschi, N. (2020). La Vulnerabilidad como Condición del Conocimiento en Investigación en Psicología Social. Psicologia: Ciência e Profissão, 40, 1-16.

https://doi.org/10.1590/1982-3703003213073 